\title{
Chemically Modified Field Effect Transistors To Monitor Ion Concen- tration in Nutrient Solutions
}

\author{
Th.H. Gieling ${ }^{1}$, J.F.J. Engbersen ${ }^{2}$ and J.J.W. Westra ${ }^{3}$ \\ ${ }^{1}$ IMAG-DLO, P.O. Box 43, 6700 AA, Wageningen, The Netherlands \\ ${ }^{2}$ MESA Research Institute, P.O. Box 217, 7500 AE Enschede, The Netherlands \\ ${ }^{3}$ PRIVA Hortimation, Zijlweg 3, De Lier, Netherlands
}

Keywords: closed growing system, isfet, chemfet, polysiloxane membrane, callix[4]arene, crown ether ionophore

\begin{abstract}
Closed soilless growing systems are introduced on a large scale in horticultural production, to decrease environmental pollution and to increase efficiency and product quality. Applying closed growing systems needs precise knowledge of the composition of the recirculating nutrient solution. This paper presents basic principles of a measuring system, which can monitor continuously the concentration of nutrients in water. The sensor system is based on the chemically modified field effect transistor (CHEMFET) that replaces current methods of discontinuous sampling followed by analysis in the laboratory. For obtaining sensors of high durability, polysiloxane membranes have been developed which contain different side groups to tune their intrinsic properties. These polysiloxane membranes show good performance in lifetime experiments. The ion selectivity has been tuned by incorporation of various novel ion receptor molecules, yielding sensors with high selectivity's for sodium, potassium, calcium, nitrate, phosphate and dihydrogen phosphate.
\end{abstract}

\section{INTRODUCTION}

Soilless growing systems are developed to decrease the excessive spread of soil born pathogens, to improve growth by a better control, to save energy and to increase product quality. Very recently the argument was added to increase a more efficient use of water, nutrients and pesticides in order to decrease emission to the environment. In greenhouse production, the pursue of high product quality is the major item. Improvement of quality starts with the control of the production process, which includes - next to climate variables - water supply and nutrient application (Stanghellini et al., 1996).

At first, the reasons for putting vegetables, flowers and fruits in sheltered or covered conditions - and control the application of artificial heating, lighting, $\mathrm{CO}_{2}$, water and fertilisers were found in boosting production, minimising bbour cost and producing year round. Since nowadays the products are sold on a more and more exacting market, the improvement of quality of the product - in all its aspects - is the major goal. Next to the more common quality aspects - like flavour, smell, colour, texture, tenability, firmness, etc. - the feature that the process of growing in itself should not do any harm to the environment or in any other way endanger public health, is seen as a modern additional alternative quality aspect. To fulfil this latter aspect, the traditionally open systems are changed into growing on artificial substrates in closed systems.

Growing horticultural crops in artificial media on a large scale was first developed in Scandinavia and was introduced in The Netherlands approximately in 1975 (Sonneveld, 1988). Adapting growing systems from soil-grown crops to soilless cultures is a tendency not only observed in The Netherlands but also in major horticultural areas abroad. The reasons for this remarkable shift from growing in soil to growing in artificial media are to be found in the urge to avoid disinfecting of the soil with highly toxic chemicals, to save on expensive raw materials and to improve productivity and quality of the crop.

However, rockwool systems show some drawbacks also. A supply of an excess of water to the plants is needed because of a substantial difference in transpiration between plants, an uneven supply of water per plant (due to inaccuracy of the trickle irrigation system) and accumulation of sodium, chloride and nutrients in the rockwool slabs. In open growing systems this ex- 
cess water will run-off freely and pollute the surface water and the sub-soil aquifers. If the drainage water is collected in a system of gullies and recycled, this form of environmental pollution and loss of water and fertilisers can be solved.

Due to considerable variation in nutrient and/or water uptake by the plants (Gieling et al., 1989) - and in contrast with current methods of discontinuous sampling followed by analysis in the laboratory - it is preferable to measure continuously on-line the composition of the drainage water. Furthermore, knowledge of nutrient uptake by the plants, determined from on-line composition measurements of irrigation water and drainage water, could lead to better understanding of plant-physiology and improve control of quality and quantity of production. Figure 1 shows an ideal layout of a closed-loop growing system with monitoring and control for water and nutrient supply. Although research has been done to apply commercial electrodes (Albury et al., 1988; Heinen, 1991), it is hard to find continuous measurement systems which comply with the demands of horticulture. In addition, novel miniaturised sensors for the (on-line) detection of low concentrations of ions in aqueous solution can find useful application in many areas, e.g. water quality monitoring, localisation of environmental pollution and biomedical analysis. Until now, such miniaturised sensor systems of sufficient stability had not been fully developed for the majority of analyses. As a consequence, hitherto, analysis is carried out with conventional techniques like chromatography, atomic absorption, emission spectrometry and various wet analytical techniques.

Innovative technology in semiconductor materials, micro-engineering, and molecular engineering show great promise for the fabrication of micro-sensors by IC technology (Engbersen and Reinhoudt, 1994). Nowadays, solid state $\mathrm{pH}$-sensors based on ion-sensitive field effect transistors are commercially available and soon it is expected that these will be followed by the commercial availability of chemically modified field effect transistors (chemfet) capable to detect activities of other ionic species in solution (Engbersen et al.,1997)

\section{MATERIALS AND METHODS}

\section{The Isfet as an Electronic Device}

The measurement system, which meets the horticulture requirements for the purpose of the research project that is described in this paper, was based on ion-selective field effect transistors (Gieling and Van den Vlekkert; 1996, Van den Vlekkert, 1988; Van den Vlekkert and Kouwenhoven, 1988). An isfet is a member of the family of MOSFET's, from which the gate electrode is replaced by a reference electrode, the solution to be measured and optionally an ion-selective material layer deposited on top of the gate insulator (Fig. 2). As the basic pH sensitive isfet, a back-side contacted isfet was developed with alumina as $\mathrm{pH}$ sensitive insulator. The advantages of back-side contacting over more conventional isfet's, are the easy encapsulation and the flexibility in choice of membrane materials. Prior to encapsulation of a conventional isfet, wires have to be bonded to the contact pads. Then, in order to insulate these wires from the solution, they are covered with epoxy. The remaining part of the chip is also insulated with epoxy, only the gate area is left open. The backside contacted isfet's, as are used in the flowthrough configuration (Fig. 3), need neither bondwiring nor epoxy encapsulation.

The isfet's were operated in the constant current mode. A sample solution from the irrigation system of a tomato culture or one out of two calibration solutions was measured automatically. Simultaneously the water temperature was measured. The $\mathrm{mV}$ output of the isfet was transformed into $\mathrm{pH}$ and $\mathrm{pK}$ activity by means of an algorithm (Van den Vlekkert and De Rooij, 1988), which also corrects for effects of temperature and drift. To select any combination of ions to be measured, each sensor is packaged in a single packaging cell (Fig. 3), that can be stacked with more cells in a flow-through system. Due to the high requirements with respect to accuracy and maintenance level, automatic in-line calibration was used.

A simple but smart circuit (Fig. 4) transforms the changing channel resistance of the isfet into proper electronic information. This circuit keeps the current $\mathrm{G}$ (Fig. 2) and the voltage across the isfet $\left(\mathrm{V}_{\mathrm{ds}}\right)$ at a constant value. Both parameters affect the electronic functioning of the isfet. $\mathrm{G}_{\mathrm{b}}$ influences the transconductance $\mathrm{g}_{\mathrm{n}}$ (electrical sensitivity) and $\mathrm{V}_{\mathrm{ds}}$ influences the drain conductance $\mathrm{g}_{\mathrm{d}}$ (output resistance). Since the voltages at both input terminals of the operational 
amplifier are the same (due to feedback), voltage $V_{R 3}$ equals $V_{\text {ref }}-V_{R 2}$. This is a constant value since both $V_{\text {ref }}$ and $V_{R 2}$ are constant. As a result a constant current $\left(I_{d}=V_{R 3} / R_{3}\right)$ is superimposed on the isfet by the feedback action of the operational amplifier. The output impedance of the circuit is very low (the same as $Z_{0}$ of the operational amplifier). Now the output voltage reflects accurately the ion activity of the measurant.

\section{Chemically Modified Field Effect Transistors (CHEMFET's)}

Basically, the chemfet is a special modification of an isfet. The latter shows sensitivity for the activity of hydrogen ions in solution, whilst the former is sensitive to other ionic species in solution (Holterman et al., 1990). The measurement principle of isfet's is - like for the ion selective electrode and glass electrode - based on potentiometric determination of ion activities in aqueous solutions. This detection technique is particularly useful in cases where a large dynamic range of ion activities has to be measured. isfet's have some important advantages compared to ion-selective membrane electrodes as fast response time, low noise level, small size and opportunities for mass production. The conductance between source and drain of a semiconductor is measured as a function of the electrical field perpendicular to the gate oxide surface (Fig. 2). In contact with an aqueous solution, the state of ionisation of the surface $\mathrm{SiOH}$ groups of a $\mathrm{SiO}_{2}$ gate oxide in an aqueous solution determines the surface potential and therefore the source-drain current in the transistor. A change in $\mathrm{pH}$ of the solution will produce a change in surface potential that can be measured by the change in channel conductance of the transistor. Typical $\mathrm{pH}$ responses thus obtained are $37-40 \mathrm{mV} / \mathrm{pH}$.

Detection of other ionic species than protons needs the introduction of ion receptors that can selectively bind these species. The intrinsic $\mathrm{pH}$ sensitivity has to be suppressed that causes dissociation of the silanol groups at the gate oxide surface. Covering of the gate oxide of an isfet with a plasticised PVC membrane, that contains the potassium-selective natural ionophore valinomycin, already gives a good potassium response upon variation of the potassium concentration. However, this construction has the severe drawback, that the physical adhesion of the membrane to the surface of the semiconductor is not stable. Furthermore, the plasticiser and ionophore leach slowly from the membrane upon prolonged contact of the sensor with the aqueous solution. Moreover, such a sensor suffers from interfering $\mathrm{pH}$-sensitivity (and carbon dioxide sensitivity) due to the uncontrolled ionisation of the surface silanol groups of the gate oxide. The latter problem can be overcome by placing a buffered hydrogel between gate oxide and sensing membrane (Sudholter et al., 1990). A layer of polyhydroxyethylmethacrylate (polyHEMA) has been attached covalently to the gate oxide surface by photopolymerising the monomer on the gate oxide, which was pre-treated with methacryloylpropyltrimethoxysilane. The methacrylated siloxane groups on the surface ensure the covalent binding of the hydrogel (Fig. 5).

In the next step of sensor preparation the poly-HEMA layer was covered with a sensing membrane. For a limited life time plasticised PVC membranes can give quite satisfactory results with ionophores as sensing membranes, no $\mathrm{CO}_{2}$ and $\mathrm{pH}$ interference and a low noise signal. A durable sensor, however, requires the chemical attachment of the sensing membrane to the semiconductor and a membrane material that does not need a plasticiser.

Covalent attachment to the membrane matrix of the electro-active components in the sensing membrane, prevents them from leaching out of the membrane. Requirements which are needed to produce a sensing membrane suitable for these purposes are:

- The sensing membrane must be an elastomer (glass transition temperature below zero).

The membrane must be moderately hydrophobic, i.e. it must possess a low partition of ions from the aqueous phase but must have sufficient conductivity in order to dbtain fast response times. For the permselectivity of the analyte ions, ionic sites of opposite charge must be present in the membrane or allowed to be added. The presence of charged species in the membrane also lowers the electrical resistance of the membrane.

- The electro-active components in the sensing membrane, i.e. receptor molecules and ionic sites, have to be co-valently bound to the membrane matrix in order to prevent leaching out.

- In order to make sensor fabrication compatible with IC-technology, linkage of all com- 
ponents in the membrane matrix and attachment of the membranes to the gate oxide surface must occur by photopolymerisable processes.

Recently, a reproducible synthesis for well-structured siloxane terpolymers was developed (Engbersen et al., 1997), based on anionic copolymerisation of cyclotrisiloxanes (Fig. 5). The covalent attachment of the membrane to the transducing part of the sensor can be enabled by the photopolymerization of the methacrylate groups.

The crosslinking of the methacrylate groups also enhances the mechanical strength of the membrane. The new polymers offer opportunities to tune the polarity and the character of the membrane by changing the amount and type of polar substituents. These changes can have a profound effect on the partition of various ions between sample and membrane phase, resulting in changes in the selectivity of the sensor.

Receptors applied in sensor membranes should posses high selectivity, especially over interfering ions that will possibly also be present in high concentrations in the sample. Furthermore, the receptor molecule must be lipophilic in order to make it soluble in the membrane matrix and to prevent fast leaching to the contacting aqueous solution. Calix[4]arene (Fig. 6-1) is a versatile lipophilic three-dimensional building block that can be functionalised with various ligating substituents for selective ion binding and can be provided with a functional group that enables covalent anchoring to the membrane matrix.

The selectivity of the receptor can be influenced by the type and number of substituents and the conformation of the calix[4]arene. For example, functionalisation of the calix[4]arene at the lower rim with amide moieties (Fig. 6-2) results in the right positioning of the co-ordinating carbonyl and phenol oxygens atoms for complexation of $\mathrm{Na}^{+}$with selectivity over other alkali cations. The selectivity of $\mathrm{Na}^{+}$over $\mathrm{K}^{+}$can even be improved by the use of two diametrically positioned amide ligands instead of four, in combination with two ester ligands (Fig. 6-3).

A crown ether moiety can easily be combined with the calix[4]arene building block. The pre-organisation of the binding cavity of the crown ether by the calix[4]arene skeleton enhances the binding selectivity and the molecule becomes more lipophilic. For $\mathrm{K}^{+}$selective sensors, a number of calix[4]arene crown ether ionophores were developed with five oxygen atoms in the crown ether bridge. These receptors clearly show the influence of the conformation of the calix[4]arene on the selectivity. The cone conformer (Fig. 6-4) has the lowest selectivity of $\mathrm{K}^{+}$ over $\mathrm{Na}^{+}\left(\log _{\mathrm{K}, \mathrm{Na}}^{\mathrm{pot}}=-2.5\right)$. The selectivity of the partial cone conformer (Fig. 6-5) is much better $\left(\log _{\mathrm{K}, \mathrm{Na}}^{\mathrm{pot}}=-3.9\right)$, but the highest $\mathrm{K}^{2+}$ selectivity was obtained for 1,3-alternate calix[4]arene $\left(\log _{\mathrm{K}, \mathrm{Na}}^{\mathrm{po}}=-4.2\right)($ Fig. 6-6).

The durability of the sensors have been tested by the exposure of these sensors to a continuously refreshed stream of tap water $\left(25 \mathrm{~mL} \cdot \mathrm{min}^{-1}\right)$. The chemfets were conditioned in a $0.1 \mathrm{M} \mathrm{NaC} 1$ solution for one night before measuring their characteristics (i.e. selectivity and sensitivity). The polysiloxane based chemfets retained their $\mathrm{Na}^{+}$selectivity in the presence of different alkali and alkaline earth metal ions for a period of more than 40 weeks. Despite of the decrease in $\mathrm{Na}^{+} / \mathrm{K}^{+}$selectivity from -2.6 to -1.4 after 40 weeks, the chemfets still have (near) Nernstian responses. Even after 40 weeks of continuously exposure to streaming tap water the chemfets are still very selective $\left(\log \mathrm{K}_{\mathrm{Na}, \mathrm{j}}=-3.0\right.$ and -2.9) for $\mathrm{Na}^{+}$in the presence of $\mathrm{Mg}^{2+}$ and $\mathrm{Ca}^{2+}$ ions, respectively. Similar results have been obtained with nitrate- selective chemfets, incorporating a quaternary ammonium groups covalently bound polysiloxane membrane and with potassium-selective chemfets incorporating covalently bound crown ether analogues.

\section{DISCUSSION AND CONCLUSION}

The problems concerning drift and temperature sensitivity can be solved with automatic calibration (Fig. 7). An accuracy of better than $10 \%$ (in $\mathrm{mMol} / \mathrm{L}$ ) can be easily realised. Due to the small size of the sensors and the reproducible correction factors only small amounts of calibration solutions are necessary, which is an advantage of the applied technology.

The isfet can be successfully applied in horticulture, if the advantages of this family of sensors are exploited completely. It is shown that electrode properties remain verisimilar over a considerable amount of time due to the sensor construction, the durability of the novel membranes and in-line calibration. Furthermore, the simple - but smart - electronic signal conditioning circuit ensures a low impedant output signal of the sensors, which means that the signal is not 
susceptible to electrical noise.

Now, since isfet's become available for more ions (sodium, potassium, calcium, nitrate and dihydrogen phosphate), a continuous control of the irrigation and drainage water can be realised. In comparison with $\mathrm{pH}$ and $\mathrm{EC}$ only, a system consisting of $\mathrm{pH}$, potassium, calcium, nitrate, phosphate and sodium sensors will be an important improvement to control the concentration of nutrients in irrigation water.

\section{ACKNOWLEDGEMENT}

The authors wish to express their gratitude for the financial support of the Ministry of Economic Affairs, The Ministry of Agriculture, The EU-AIR III (MACQU) Program and PRIVA Hortimatimation B.V.

\section{Literature Cited}

Albery, W.J., H.J.J., Drummond, N.J., Freeman, B.D.G, Haggett, C.C, Jones, C.P., Neville, M.D. (1988). Chemical sensors and instrumentation for horticulture, in: Horticulture in high technology era, Tokyo, Japan, p. 195.

Engbersen, J.F.J. and Reinhoudt, D.N. (1994). Chemically modified field-effect transistors for measurement of ion activities in aqueous solution. Analusis Magazine, 1994, V22, no 9, pp M16-M18.

Engbersen, J.F.J., Antonisse, M.M.G, Lugtenberg, R.J.W. and Reinhoudt, D.N. (1997). Chemically modified field-effect transistors for measurement of ion activities in aqueous solution. J.Electrochem.Soc., Paris 1997 (in print).

Gieling, Th.H., van Os, E.A., de Jager, A. (1989); The application of Chemo- and Bio-sensors for soilless cultures. Acta Hort. 230, pp. 357-362.

Gieling, Th.H. and van den Vlekkert, H.H. (1996). Application of isfets in closed-loop systems for greenhouses. Adv. Space Res. Vol 18, No. 4/5, pp135-138, Pergamon.

Heinen, M., (1991). Control of composition of nutrient solution in NFT systems, Experiment and Simulation. Acta Hort. 304, pp 273-291

Holterman, H.A.J., Honig, G.W.N, Sudholter, E.J.R., Reinhoudt, D.N., van den Vlekkert, H.H (1990). Chemically modified isfets for the selective sensing of potassium and calcium in mixed electrolyte solution, in: Proc. 3th. Int. Meeting on Chemical Sensors, Cleveland, Ohio, USA, p. 40.

Sonneveld, C. (1988). Rockwool as a substrate in protected cultivation, in: Horticulture in high technology era, Tokyo, Japan, p. 173.

Stanghellini, C., van Meurs, W.Th.M, Corver, F.J.M., van Dullemen, E. and Simonse, L. (1996). Combined effect of potential evaporation and solute content of irrigation water on quality parameters of yield of greenhouse tomato. In: IAV Hassan II and CIHEAM/MAI-B Mediterranean colloquium on protected cultivation. Agadir Morocco, pp a4.1-a4.14

Sudholter, E.J.R., van der Wal, P.D., Skowronska-Ptasinska, M., Van den Berg, A., Bergveld, P. and Reinhoudt, D.N (1990). Modification of isfets by covalent anchoring of poly (hydroxyethyl methacrylate) hydrogel. Introduction of a thermodynamically defined semiconductor sensing membrane interface, Anal. Chim. Acta, 230, p. 59.

Van den Vlekkert, H.H. and de Rooij, N.F.,1988. Design, fabrication and characterization of $\mathrm{pH}$ sensitive isfets, Analusis, Vol.16 nr.2, p. 110.

Van den Vlekkert, H.H., Kloeck, B., Prongue, D., Berthoud, J., Hu, B., de Rooij, N.F., Gilli, E. and de Crousaz, $\mathrm{Ph}, 1988$. A pH isfet and an integrated $\mathrm{pH}$-pressure sensor with backside contacts, in: Sensors and Actuators, Vol. 14 no. 2, p.165.

Van den Vlekkert, H.H 1992. Ion Sensitive Field Effect Transistors. Acta Hort. 304, p.113.

Van den Vlekkert, H.H. and Kouwenhoven, J.P.M.,1988. Application of isfet's in closed loop systems for horticulture. Acta Hort. 304, p.309. 


\section{Figures}

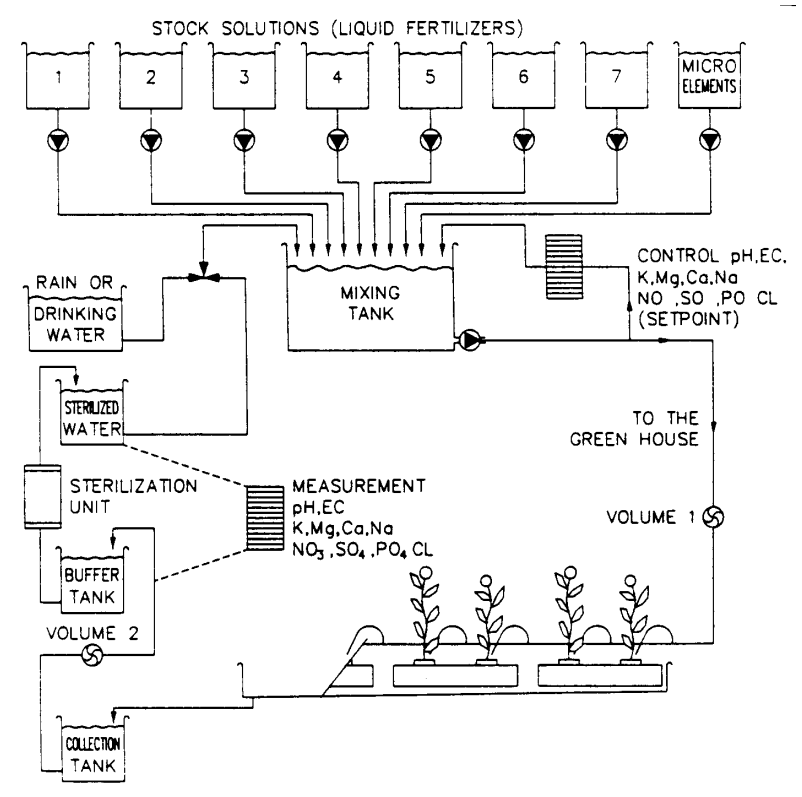

Fig. 1. Layout of a closed loop system with ion concentration control.

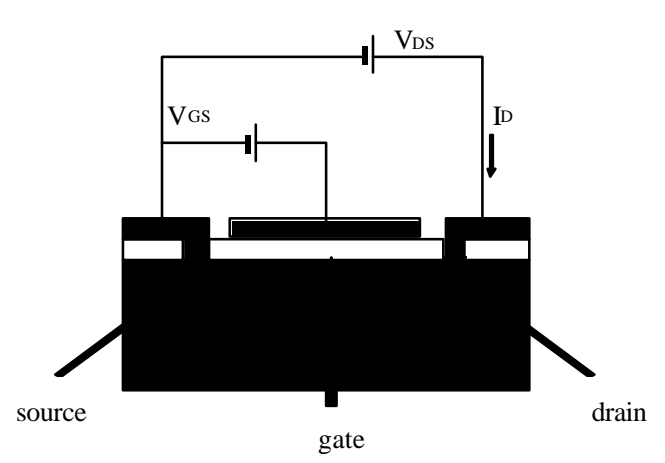

MOSFET

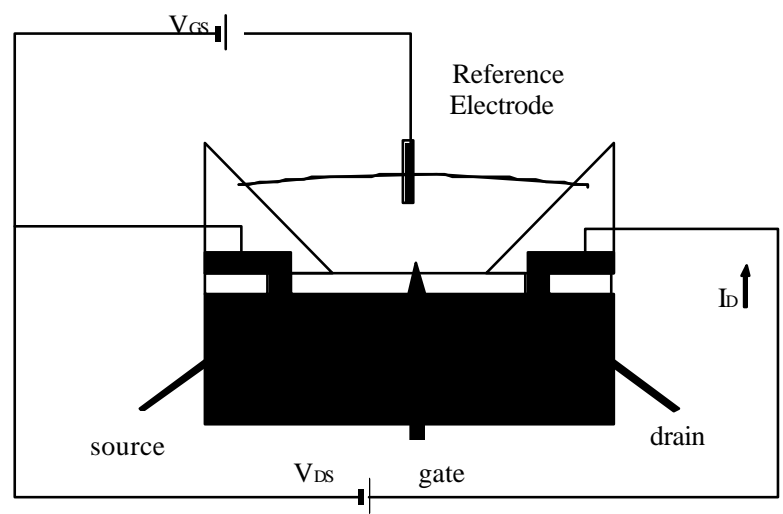

ISFET

Fig. 2. Schematic presentation of a MOSFET and an ISFET. 


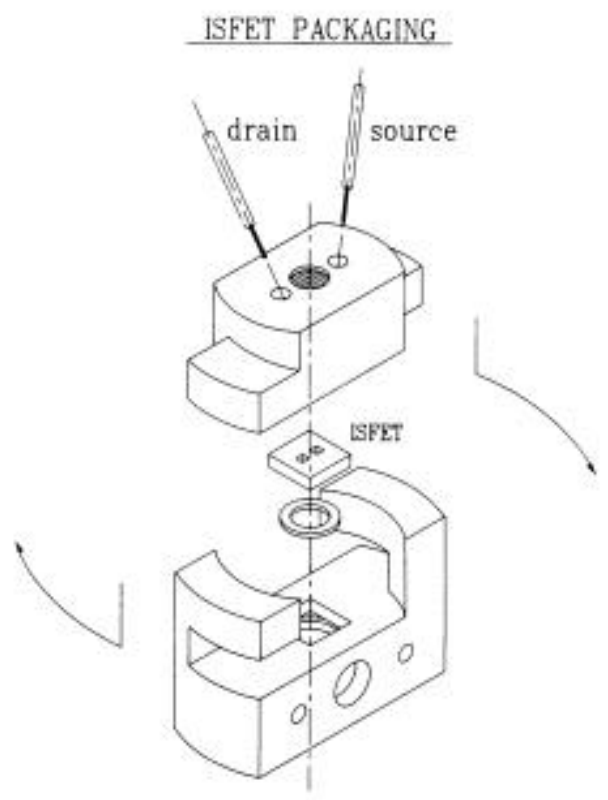

Fig. 3. Packaging of the isfet chip.

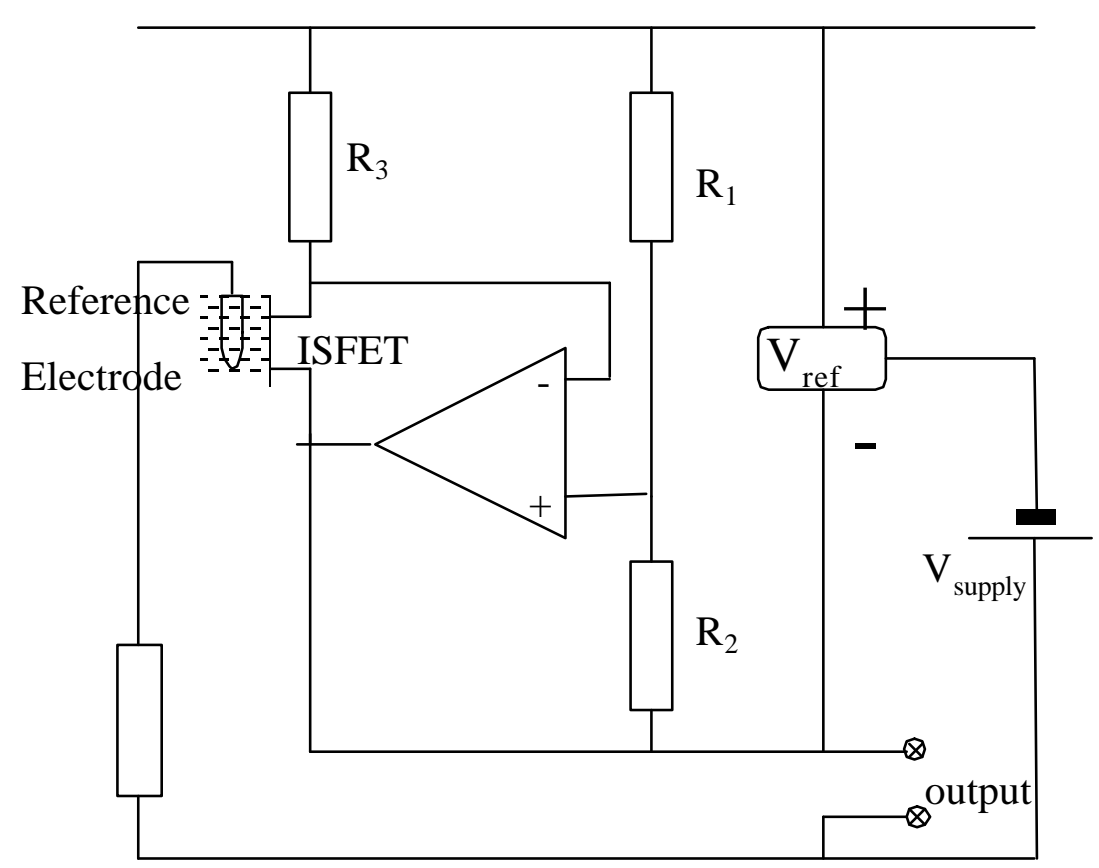

Fig. 4. The isfet amplifier circuit. 


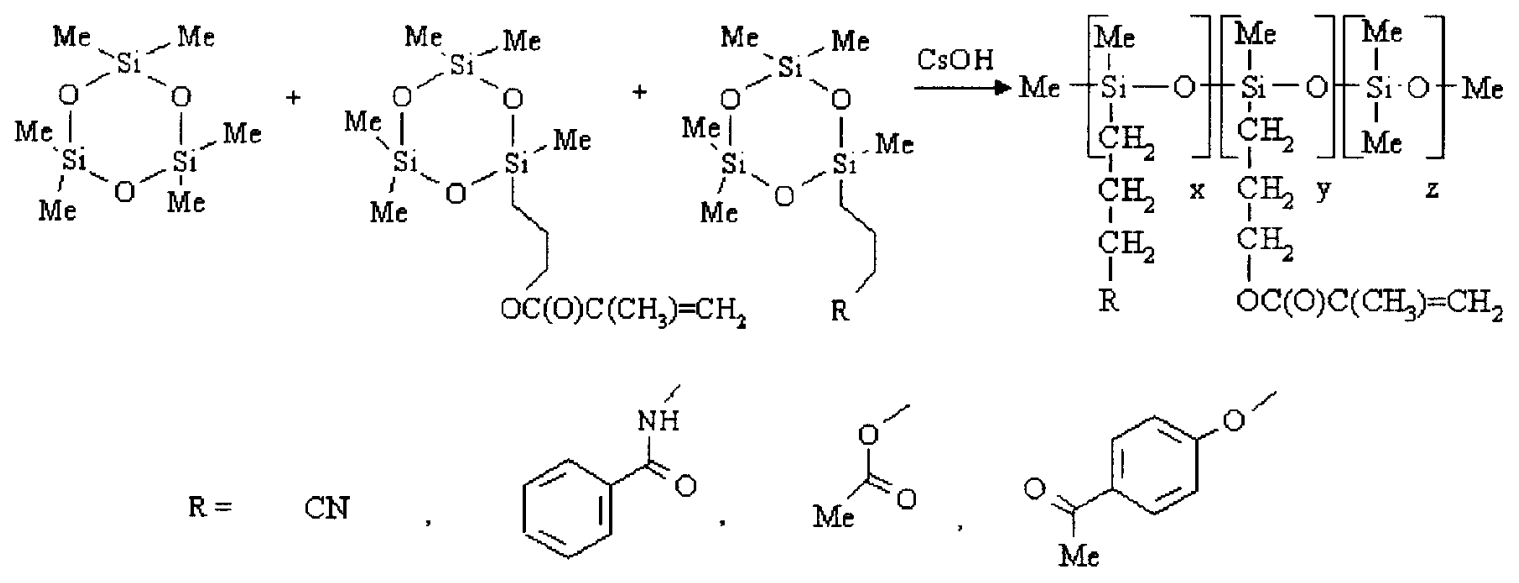

Fig. 5. Anionic copolymerisation of different cyclotrisiloxanes.
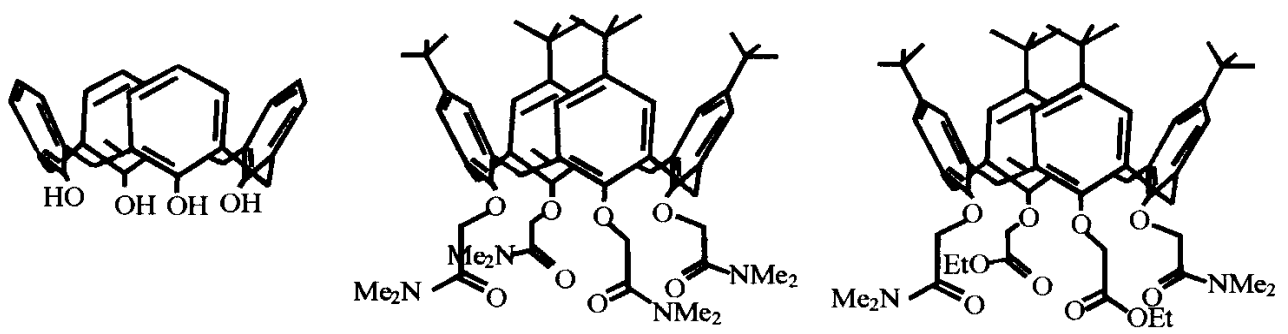

1

2

3

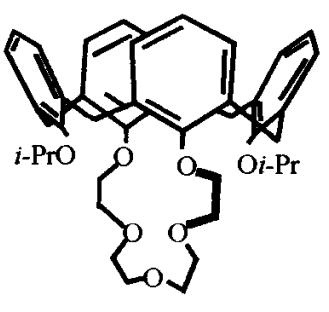

4

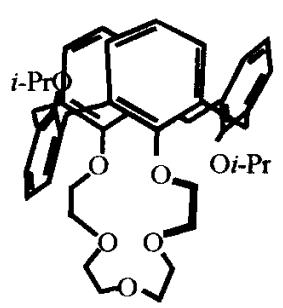

5

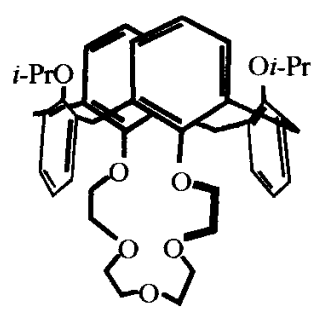

6

Fig. 6. Calix[4]arene and its functionalisations. 